\title{
Endocrine side effects of broad-acting kinase inhibitors
}

\author{
Maya B Lodish ${ }^{1,2}$ and Constantine A Stratakis ${ }^{1,2}$
}

\begin{abstract}
${ }^{1}$ Section on Endocrinology Genetics, Program on Developmental Endocrinology Genetics, Eunice Kennedy Shriver National Institute of Child Health and Human Development (NICHD) and ${ }^{2}$ Pediatric Endocrinology Inter-Institute Training Program, National Institutes of Health (NIH), 10 Center Drive, CRC Room 1-3330, Bethesda, Maryland 20892, USA
\end{abstract}

(Correspondence should be addressed to M B Lodish at 10 Center Drive, CRC Room 1-3330, Bethesda, Maryland 20892, USA; Email: lodishma@mail.nih.gov)

\begin{abstract}
Targeted therapy in oncology consists of drugs that specifically interfere with abnormal signaling pathways that are dysregulated in cancer cells. Tyrosine kinase inhibitors (TKIs) take advantage of unique oncogenes that are activated in certain types of cancer, and also target common mechanisms of growth, invasion, metastasis, and angiogenesis. However, many kinase inhibitors for cancer therapy are somewhat nonselective, and most have additional mechanisms of action at the cellular level, which are not completely understood. The use of these agents has increased our knowledge of important side effects, of which the practicing clinician must be aware. Recently, proposed endocrine-related side effects of these agents include alterations in thyroid function, bone metabolism, linear growth, gonadal function, fetal development, and glucose metabolism, and adrenal function. This review summarizes the most recent data on the endocrine side effects of TKIs.
\end{abstract}

Endocrine-Related Cancer (2010) 17 R233-R244

\section{Introduction}

Dysregulated kinase signaling is invariably involved in the pathogenesis of all types of malignancies. Therefore, enormous efforts are being devoted to the development of small molecule drugs that regulate the abnormal cancer 'kinome'. Protein tyrosine kinases (TKs) catalyze the phosphorylation of specific tyrosine residues on their substrate proteins. TKs are key regulators of signaling pathways involving cellular proliferation, differentiation, and apoptosis (Schlessinger 2000, Krause \& Van Etten 2005). Small molecule TK inhibitors (TKIs) are rationally designed compounds that affect TK-dependent oncogenic pathways. They are promising treatments for the therapy of malignant disease, and offer excellent targets for selective inhibition (Krause \& Van Etten 2005). These agents potentially provide a relatively high therapeutic window with low toxicity in comparison with conventional cytotoxic chemotherapy. However, as we gain experience with the use of TKIs, we are becoming aware of important side effects. This review will outline the endocrine-related side effects associated with TKIs in order to bring the practicing clinician up to date with the current status of the field.

TKIs have become more widespread in use as targeted therapy for a variety of malignancies (Zhang et al. 2009). One of the first TKIs to demonstrate effectiveness, imatinib, has activity against the BCR-ABL oncoprotein, and has been successful in the treatment of chronic myeloid leukemia (CML; Ren 2005, Jabbour et al. 2007). Imatinib is also approved for the treatment of recurrent or metastatic gastrointestinal stromal tumors (GISTs), in which the c-KIT or platelet-derived growth factor receptor $\alpha$ (PDGFR $\alpha)$ TKs may be constitutively activated (Rubin et al. 2007). More recently, TKIs have been used in the treatment of neuroendocrine tumors (Kulke et al. 2008, Raymond 2010). Oncogenic kinases that have been implicated in the development of thyroid cancer, such as rearranged during transfection (RET) protooncogene and B-RAF (a proto-oncogene serine/ threonine protein kinase), have emerged as targets for TKI therapy (Lodish \& Stratakis 2008, Sherman $2009 a$ ). For patients with medullary or differentiated thyroid cancer unresponsive to conventional treatment, 
TKIs are currently being used in a number of clinical trials (Gupta-Abramson et al. 2008, Sherman et al. 2008, Fox et al. 2009, Kloos et al. 2009, Schlumberger et al. 2009, Wells et al. 2010). Further use of these agents for other types of malignancies is outlined in Table 1.

There are more than 500 different protein kinases encoded by the human genome; almost all of these kinases phosphorylate substrate proteins via their catalytic ATP-binding region (Daub 2010). The TKs include the epidermal growth factor receptor (EGFR), the vascular endothelial growth factor receptors 1 and 2 (VEGFR1 and VEGFR2), and the downstream signaling mitogen-activated protein kinase/extracellular signal-related kinase (MAPK/ERK) pathway, among others (Sebolt-Leopold 2008, Tortora et al. 2008). PDGFRA, fibroblast growth factor receptor, and serine-threonine kinase mammalian target of rapamycin are additional kinases implicated in oncogenesis (Alvarez et al. 2006, Meric-Bernstam \& GonzalezAngulo 2009). In papillary thyroid cancer (PTC), somatic rearrangement of the RET proto-oncogene leads to activated forms of RET, and germline mutations of the RET receptor are pathogenic in medullary thyroid cancer (MTC; Ciampi \& Nikiforov
2007, Wells \& Santoro 2009). Activation of the B-Raf proto-oncogene serine/threonine protein kinase occurs frequently in adult PTC (Xing 2005).

Among the different classes of protein kinases, there is a conservation of the structure of the ATP-binding site. TKIs act as small molecules with structural similarity to ATP, which serve to disrupt the catalytic activation of TKs (Fig. 1). As a result of this homology, many TKIs may have inhibitory activity against a broad range of protein kinases. Many kinase inhibitors are less selective than initially thought and often affect multiple signaling pathways (Fabian et al. 2005, Karaman et al. 2008, Daub 2010).

TKIs are administered orally and cause a number of side effects including fatigue, hypertension, rash, impaired wound healing, myelosuppression, and diarrhea (Widakowich et al. 2007). The overall toxicity of TKIs, while less life-threatening than conventional cytotoxic chemotherapy, nevertheless is common, and may require dose reduction. Recently, proposed endocrine-related side effects of these agents include alterations in thyroid function, bone metabolism, linear growth, gonadal function, fetal development, and glucose metabolism, and adrenal function (Fig. 2).

Table 1 Major tyrosine kinase inhibitors in clinical use

\begin{tabular}{|c|c|c|c|}
\hline Drug & Tumors treated & Main tyrosine kinases targeted & $\begin{array}{l}\text { Stage of clinical } \\
\text { development }\end{array}$ \\
\hline Imatinib & $\begin{array}{l}\text { CML, chronic eosinophilic leukemia, } \\
\text { Philadelphia-positive ALL, and GIST }\end{array}$ & bcr-abl, c-KIT and PDGFRA & FDA approved \\
\hline Dasatinib & CML and Philadelphia chromosome-positive ALL & $\begin{array}{l}\text { SRC family TK, bcr-abl, c-KIT and } \\
\text { PDGFRA }\end{array}$ & FDA approved \\
\hline Nilotinib & CML & bcr-abl, c-KIT and PDGFRA & FDA approved \\
\hline Sunitinib & GIST and RCC & VEGFR2, PDGFRB, c-KIT and FLT3 & FDA approved \\
\hline Sorafenib & RCC and hepatocellular carcinoma & RAF/MEK/ERK VEGFR2/PDGFRs & FDA approved \\
\hline Gefitinib & NSCLC & EGFRs & FDA approved \\
\hline Erlotinib & NSCLC pancreatic cancer & EGFRs & FDA approved \\
\hline Lapatinib & HER2-positive breast cancer & $\begin{array}{l}\text { EGFR, ErbB2, Erk-1 and }-2 \text { and } \\
\text { AKT kinases }\end{array}$ & FDA approved \\
\hline Axitinib & $\begin{array}{l}\text { Pancreatic, breast RCC, NSCLC, melanoma, } \\
\text { thyroid and renal }\end{array}$ & VEGFRs and PDGFRs & Phases II-III \\
\hline Vandetanib & NSCLC, myeloma, thyroid cancer and glioma & VEGFRs, EGFRs and RET & Phases II-III \\
\hline Vatalanib & $\begin{array}{l}\text { Colorectal cancer, pancreatic, neuroendocrine } \\
\text { and glioblastoma multiforme }\end{array}$ & VEGFRs, PDGFRs, c-KIT and c-Fms & Phases II-III \\
\hline AEE788 & Glioblastoma multiforme & EGFR, HER2 and VEGF2 & Phase I/II \\
\hline Motesanib & $\begin{array}{l}\text { GIST, breast cancer, neuroendocrine tumors, } \\
\text { thyroid, colorectal and NSCLC }\end{array}$ & VEGFRs, PDGFRs, c-KIT and RET & Phase II/III \\
\hline Dovitinib & Melanoma, $\mathrm{RCC}$, breast and prostate & $\begin{array}{l}\text { FGFR3, VEGFR, PDGFR3, FLT-3 } \\
\text { and c-KIT }\end{array}$ & Phase I/II \\
\hline Tivozanab & RCC, breast, colorectal and NSCLC & & Phase II/III \\
\hline
\end{tabular}

All information may be accessed at http://www.cancer.gov; CML, chronic myeloid leukemia; ALL, acute lymphoblastic leukemia; GIST, gastrointestinal stromal tumor; RCC, renal cell carcinoma; NSCLC, nonsmall cell lung carcinoma; EGFR, epidermal growth factor receptor; PDGFR, platelet-derived growth factor receptor; VEGFR, vascular endothelial growth factor receptor; FLT-3, Fmsrelated tyrosine kinase 3 . 


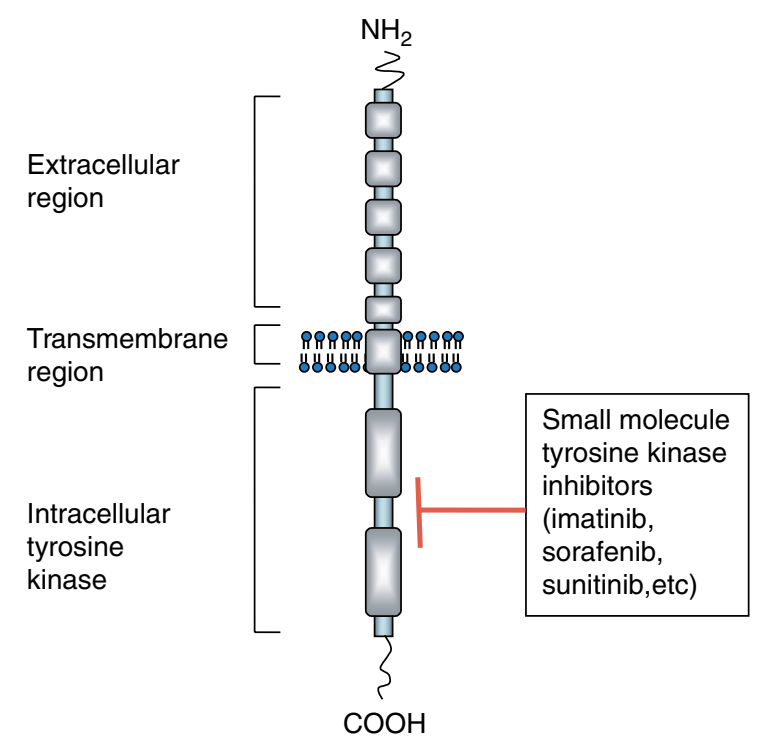

TKIs prevent receptor phosphorylation by competing with ATP binding in the activation domain, inhibiting downstream signal transduction

Figure 1 Schematic of structure and function of tyrosine kinase receptor and its small molecule inhibitors.

\section{Thyroid function}

The increased use of TKIs has raised the awareness of adverse affects on thyroid hormone function and/or thyroid hormone metabolism, as outlined in Table 2. As a result of these studies, it is now recommended that all patients starting therapy with TKIs have their thyroid function tested prospectively (Sherman 2009b, Torino et al. 2009). Other types of anticancer therapies have also been associated with thyroid dysfunction, including radiation to the pituitary and thyroid, and treatment with synthetic retinoid $\mathrm{X}$ receptor agonist autoantibodies (Sherman et al. 1999, Garcia-Serra et al. 2005, Darzy \& Shalet 2009). Hypothyroidism has also been reported after therapy with the angiogenesis inhibitor thalidomide (Badros et al. 2002). Therapy with interleukin-2 (IL-2) and interferon- $\alpha$ has been reported to induce thyroid dysfunction and thyroid autoantibodies (Weijl et al. 1993).

The effect of TKIs in thyroid function was first noted in 2005 with the use of imatinib, which inhibits the TK activity of the ABL, c-KIT, and PDGFRA kinases. In eight MTC patients treated with imatinib, all of whom had previously undergone thyroidectomy, marked elevations in TSH up to a mean of $384 \pm 228 \%$ of the upper limit were noted (de Groot et al. 2005). Free thyroxine $\left(\mathrm{T}_{4}\right)$ was decreased but generally remained within the reference range. Despite doubling the average dosage of levothyroxine, thyroid functions were normalized in only three out of eight patients. The authors described associated symptoms that could be considered consistent with hypothyroidism, including fatigue and edema. However, they also pointed out that it was difficult to distinguish whether these were caused by hypothyroidism, other underlying disease, or imatinib itself. Interestingly, in this initial description of thyroid dysfunction associated with TKIs, the patients had no thyroid glands (since they had undergone thyroidectomies for their tumors); therefore, 'thyroid dysfunction' could be better described as 'alterations in TSH and free $\mathrm{T}_{4}$ ' or 'worsening postsurgical hypothyroidism', because the thyroid gland itself could not be implicated in the pathophysiology. One study evaluating the thyroid function of 68 patients with CML and intact thyroid glands who received imatinib did not find any adverse effect on thyroid function, suggesting that perhaps the effect of imatinib was unique to patients surgically rendered athyroid (Dora et al. 2008). Motesanib, a TKI with inhibitory effects on VEGFR, PDGFRA, c-KIT, and RET, was also associated with marked exacerbation of postsurgical hypothyroidism in a phase II thyroid cancer trial. In this study, 60-70\% of patients exhibited elevated TSH values, with $22 \%$ of patients defined as having clinical hypothyroidism, and a mean levothyroxine dosage increase in $30 \%$ was required to maintain normal TSH levels (Pacini et al. 2007).

A number of other studies have followed thyroid functions in patients receiving TKIs who have intact thyroid glands (Table 2). Sorafenib inhibits the kinase activity of RAF, mitogen-activated protein kinase/extracellular signal-regulated kinase kinase (MEK), extracellular signal-regulated kinase (ERK), VEGFR2 and PDGFR. Tamaskar et al. studied the incidence of thyroid function alterations in patients with metastatic renal cell cancer (RCC): hypothyroidism developed in 7 of 39 patients $(18 \%)$, and was first observed 2-4 months after initiation of sorafenib.

The TKI most frequently associated with hypothyroidism is sunitinib, which targets VEGFRs, PDGFRs, KIT, and RET. Desai et al. (2006) prospectively obtained thyroid function tests (TFT)s in 42 patients with GIST who were receiving sunitinib. Abnormal elevations in TSH were seen in 26 patients (62\%), while persistent hypothyroidism was documented in 15 patients $(36 \%)$. The average length of time to first peak elevation of TSH was 50 weeks of therapy (range 12-94 weeks). The investigators were able to normalize TSH in all patients with levothyroxine therapy. The authors suggested destructive thyroiditis as a possible mechanism of sunitinib-induced hypothyroidism, as 


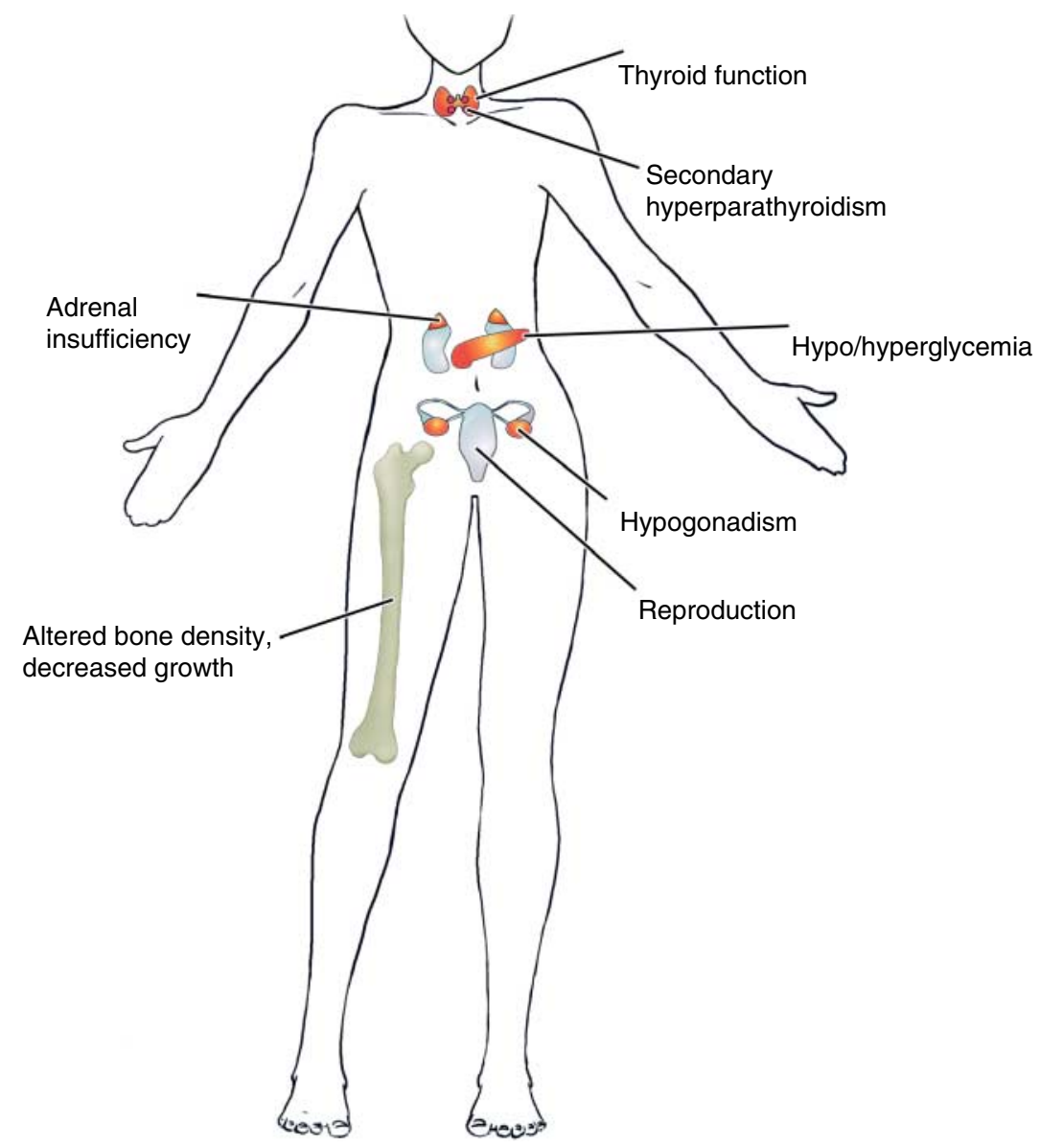

Figure 2 Endocrine organs involved in side effects of tyrosine kinase inhibitors.

6 out of 15 patients with hypothyroidism had a TSH level below $0.5 \mu \mathrm{IU} / \mathrm{ml}$ prior to developing hypothyroidism. In addition, two patients were found to have atrophic thyroid tissue on ultrasound, thought to be consistent with thyroiditis. Rini et al. (2007) evaluated thyroid abnormalities in 66 patients with RCC treated with sunitinib. The results of this study are complicated by the fact that 30 of the patients received treatment with cytokine-based therapy (Weijl et al. 1993). In total, 56 of the 66 patients $(85 \%)$ developed hypothyroidism; symptoms that can be associated with hypothyroidism, such as cold intolerance, fatigue, edema, dry skin, and thinning hair, were seen in 47 out of 66 patients (84\%). This study also proposed thyroiditis as a possible mechanism for the observed abnormalities as thyroglobulin antibodies were found in 13 out of the 44 patients in whom they were measured. Two other reports have also demonstrated sunitinib-induced hypothyroidism associated with destructive thyroiditis (Faris et al. 2007, Grossmann et al. 2008). However, a number of other studies have shown recovery of TSH values to the normal range following treatment with sunitinib, which does not support the hypothesis of destructive thyroiditis (Grossmann et al. 2008, Wolter et al. 2008).

Schoeffeski et al. (2006) measured thyroid functions in 19 patients with RCC and GIST receiving sunitinib. Of these patients, 7 out of $19(37 \%)$ showed elevated TSH during treatment, while 8 out of the $14(57 \%)$ patients went on to develop hypothyroidism after a median duration of 44 weeks. Wong et al. (2007) evaluated the prevalence of hypothyroidism in a cohort of 40 patients with GIST, $53 \%$ of whom exhibited hypothyroidism after a median of 5 months of treatment with sunitinib. This study was limited by the lack of baseline thyroid function data in the majority of patients, making it difficult to determine the true underlying incidence of thyroid dysfunction.

Martorella et al. (2006) reported a $20 \%$ incidence of hypothyroidism in a group of 39 patients with RCC treated with sunitinib; however, a complicating factor is that all patients had prior treatment with IL-2. Shaheen et al. (2006) evaluated TFTs in 55 patients with RCC, $73 \%$ of whom developed hypothyroidism. 
Table 2 Studies reporting hypothyroidism in patients receiving tyrosine kinase inhibitor (TKI) therapy

\begin{tabular}{|c|c|c|c|c|}
\hline References & Tumor type & TKI used & Subjects with TFTs $(n)$ & Hypothyroidism (\%) \\
\hline Desai et al. (2006) & GIST & Sunitinib & 42 & 36 \\
\hline Rini et al. (2007) & $\mathrm{RCC}$ & Sunitinib & 66 & 85 \\
\hline Schoeffski et al. (2006) & RCC and GIST & Sunitinib & 33 & $\begin{array}{l}37 \text { prospectively } \\
57 \text { retrospectively }\end{array}$ \\
\hline Wong et al. (2007) & GIST & Sunitinib & 40 & 53 \\
\hline Martorella et al. (2006) & $\mathrm{RCC}$ & Sunitinib & 39 & 20 \\
\hline Sabatier et al. (2009) & $\mathrm{RCC}$ & Sunitinib & 54 & 68 \\
\hline Shaheen et al. (2006) & $\mathrm{RCC}$ & Sunitinib & 55 & 73 \\
\hline Mannavola et al. (2007) & GIST & Sunitinib & 24 & 46 \\
\hline Chu et al. (2007) & GIST & Sunitinib & 36 & 14 \\
\hline Wolter et al. (2008) & RCC and GIST & Sunitinib & 59 & 27 \\
\hline Tamaskar et al. (2008) & $\mathrm{RCC}$ & Sorafenib & 39 & 18 \\
\hline de Groot et al. (2005) & GIST and MTC & Imatinib & 11 & 73 \\
\hline de Groot et al. (2007) & MTC & Imatinib & 15 & 60 \\
\hline Sherman et al. (2008) & DTC & Motesanib & 93 & 22 \\
\hline Dora et al. (2008) & CML & Imatinib & 68 & 0 \\
\hline
\end{tabular}

ALL, acute lymphoblastic leukemia, GIST, gastrointestinal stromal tumor; RCC, renal cell carcinoma; MTC, medullary thyroid cancer; DTC, differentiated thyroid cancer; CML, chronic myeloid leukemia.

Sabatier et al. performed a prospective observational analysis of hypothyroidism during sunitinib therapy in metastatic RCC and found that $68 \%$ of the 54 patients developed hypothyroidism. In a study by Mannavola et al. (2007), $46 \%$ of patients with GIST on sunitinib treatment developed hypothyroidism requiring therapy with levothyroxine, while $25 \%$ exhibited transient TSH elevation. Thyroid ultrasound scans and iodine-123 $\left({ }^{123} \mathrm{I}\right)$ thyroidal uptake were performed at the end of several periods of sunitinib treatment. They found that ${ }^{123}$ I uptake was significantly reduced at the end of treatment periods, with partial or total normalization when therapy with TKIs was discontinued. The authors suggested that the underlying mechanism of sunitinib-induced thyroid dysfunction was impaired iodine uptake.

Two cases of RCC patients diagnosed with a nodular thyroid gland were observed to have marked shrinkage of the thyroid gland during treatment with sunitinib (Rogiers et al. 2010). Thyroid gland volume reduction was measured via computed tomography (CT) scan, showing progression to near complete disappearance of the gland in one of the two patients. The authors hypothesize that TKI-induced thyroid function may be due to capillary regression induced by VEGF inhibition. A recent case report described a patient with RCC who developed hypothyroidism while on sunitinib and was found to develop an atrophic thyroid with marked reduction in vascularity (Makita et al. 2010). However, disputing these findings is a study by Mannavola et al. (2007) who performed thyroid ultrasounds on 11 patients both before and during sunitinib treatment, and did not detect changes in thyroid gland volume.
The mechanism by which TKIs cause thyroid dysfunction remains unclear. A number of in vitro and animal studies have been performed to try and characterize the mechanism of TKI-induced hypothyroidism. Wong et al. (2007) performed in vitro assays to measure the effect of sunitinib on peroxidase activity, and found that sunitinib had antiperoxidase activity $25-30 \%$ as potent as propylthiouracil. They propose that sunitinib acts directly on the thyroid gland via inhibition of peroxidase activity and thyroid hormone synthesis. Salem et al. (2008) evaluated the pathological mechanism of sunitinib-induced hypothyroidism in rat thyroid cell cultures, and found that incubation with sunitinib for $24 \mathrm{~h}$ caused a doserelated increase in ${ }^{125}$ I-iodide uptake, suggesting that inhibition of iodine uptake is unlikely to be the mechanism of sunitinib-induced hypothyroidism.

The definition of hypothyroidism was somewhat variable in the studies reviewed, and some studies lacked complete TFT data in all patients. Postulated mechanisms are presented in Table 3. Interestingly, alterations in thyroid function tests have also been observed in clinical trials of thyroid cancer patients who have undergone thyroidectomy. This would certainly argue against a direct role of the thyroid gland in the mechanism of the effect of TKIs on TSH levels. Thus, some of the proposed mechanisms to explain the elevated TSH cannot explain the observed alterations of TFTs in studies of postthyroidectomy patients. One mechanism to explain worsening TSH elevation in postthyroidectomy patients would be an indirect effect of sunitinib on the metabolism of thyroid hormone, or with thyroid hormone action at the 
Table 3 Proposed mechanisms of tyrosine kinase inhibitorinduced hypothyroidism

Decrease in enteric thyroid hormone absorption

Increased hepatic metabolism of $\mathrm{T}_{4}$ and $\mathrm{T}_{3}$

Inhibition of $\mathrm{T}_{4}$ deiodination

Impaired iodide update

Stimulation of $\mathrm{T}_{4}$ and $\mathrm{T}_{3}$ clearance

Destructive thyroiditis

Direct inhibition of thyroid peroxidase activity

Capillary regression induced by VEGF inhibition

Interference with thyroid hormone action at the pituitary gland level

pituitary level. It is plausible that the different types of TKIs have more than one mechanism affecting thyroid functions, but it remains more likely that there is a universal drug class effect of these medications that have yet to be clarified.

Unanswered questions remain regarding the optimal management of TKI-induced hypothyroidism. Baseline thyroid function tests should be performed before the initiation of TKI therapy, and TFTs should be frequently monitored during treatment with TKIs. Levothyroxine treatment should be started when clinical hypothyroidism develops. However, the management of asymptomatic subclinical hypothyroidism (TSH 5-10 $\mu \mathrm{IU} / \mathrm{ml}$ ) is uncertain in cancer patients in whom symptoms of hypothyroidism, such as fatigue, might overlap with symptoms of the malignancy and its treatment. Individuals with elevated TSH can be effectively managed with thyroid hormone replacement, such that hypothyroidism alone is not an indication for dose reduction or discontinuation of TKI therapy (Torino et al. 2009). Additional prospective clinical trials are necessary to investigate this important endocrine side effect and to determine the underlying molecular mechanism of TKI-related hypothyroidism.

\section{Altered bone density and secondary hyperparathyroidism}

A number of recent studies have demonstrated altered bone and mineral metabolism in patients receiving imatinib; however, to date, this affect has not been reported in other TKIs (Berman et al. 2006, Grey et al. 2006, Osorio et al. 2007, Fitter et al. 2008). As patients taking TKIs often continue the treatment indefinitely, clinicians need to be aware of the potential long-term effects of these agents on the skeleton. A 2-year prospective clinical study of the biochemical and skeletal effects of imatinib revealed secondary hyperparathyroidism and decreased bone turnover during prolonged treatment with imatinib (O'Sullivan et al. 2009). In nine patients with $b c r-a b l$-positive CML, therapy with imatinib was associated with a biphasic change in bone turnover, with an initial stimulation of bone formation followed by a period of suppression of bone resorption and formation. Bone mineral density in the cohort studied was stable or increased during the first 2 years of therapy, along with the development of mild secondary hyperparathyroidism (O'Sullivan et al. 2009). Two additional studies have demonstrated increased cortical bone mineralization in CML patients treated with imatinib (Fitter et al. 2008, Jonsson et al. 2008).

The effects of TKIs on bone mineral metabolism and bone remodeling are hypothesized to be due to unspecific inhibition of tyrosine kinases expressed by osteoclasts and osteoblasts, such as c-KIT and PDGFRA (Berman et al. 2006). In vitro studies have shown that the TKI dasatinib can cause dysregulation of bone remodeling via inhibition of osteoclasts (Vandyke et al. 2010). Additional in vitro studies revealed that imatinib promotes osteoblast differentiation by inhibiting PDGFR signaling and osteoclastogenesis (O’Sullivan et al. 2007).

\section{Linear growth}

Because of the small numbers of pediatric patients receiving single drug therapy with TKIs, it has not been feasible to conduct large-scale clinical trials to gain information about the effects of long-term therapy with TKIs on linear growth in childhood and adolescence. Angiogenesis is controlled in part by soluble factors such as VEGF and PDGF. Imatinib was shown to inhibit PDGF-induced cell proliferation and activity in chondrocyte cultures in vitro (Vandyke et al. 2009). In mouse models, VEGF has been linked to key steps in cartilage remodeling, ossification, and angiogenesis during endochondral bone formation (Gerber et al. 1999). Recent in vivo studies in rats showed narrowing of the growth plate at the proximal tibia in imatinibtreated animals (Vandyke et al. 2009). In a mouse model, imatinib treatment had an antiresorptive effects on osteoclasts that impaired the length of tubular bone, particularly in prepubertal animals (Suttorp et al. 2008). These studies have raised concern for the potential effects of TKIs on longitudinal growth in children.

Three recently published case studies report decelerated growth in prepubertal CML patients undergoing imatinib therapy (Mariani et al. 2008, Kimoto et al. 2009, Schmid et al. 2009). In one such case, the authors reported an 11-year-old boy who experienced a dramatic reduction in growth rate from 4.3 to $1.5 \mathrm{~cm}$ per year after initiating imatinib therapy 
(Mariani et al. 2008). In another case, a 6-year-old girl had significantly decreased growth velocity after being started on imatinib therapy for CML; the same patient returned to an increased growth rate after cessation of imatinib: during 4 years of imatinib therapy, the patient's height SDS decreased from -0.7 to -2.7 (Kimoto et al. 2009). Finally, a third case reported a 5-year-old-girl whose height fell from the 74th percentile to the 9th percentile after 3 years of treatment with imatinib (Schmid et al. 2009). Additional larger scale clinical studies are necessary to draw meaningful conclusions about the effect of imatinib and other TKIs on linear growth in children.

\section{Hypogonadism and ovarian insufficiency}

A number of case reports have presented a possible association between gynecomastia and TKI use. One described a 69-year-old patient with metastatic RCC who developed painful gynecomastia while on sunitinib therapy; this gynecomastia was partially reduced while off therapy and resumed when sunitinib was reinitiated (Ballardini et al. 2009). Another report describes a patient with CML initiated on imatinib at the age of 11 years. Beginning at age 14 , this patient had progressive increase in FSH and a decrease in inhibin-B, along with the development of gynecomastia (Mariani et al. 2008). Another report described the development of gynecomastia in a 42-year-old male on imatinib for GIST (Kim et al. 2005). In one case of gynecomastia in a 70-yearold male after treatment with dasatinib for CML, tamoxifen was added as combination therapy with subsequent reduction in gynecomastia (Caocci et al. 2008). Another study looked at testosterone levels in 38 men receiving imatinib for CML at baseline and during treatment. Seven cases of gynecomastia were noted (18\% of patients), with associated significant decrease in testosterone concentrations (Gambacorti-Passerini et al. 2003). The mechanism by which sunitinib and other TKIs may induce gynecomastia is unknown, although c-KIT and PRGFRA are expressed in the testis, and are involved in the production of testosterone (Basciani et al. 2002). Imatinib has been shown to inhibit Leydig cell tumor growth in rat models, and this may be due to the inhibition of proliferation and ligandstimulated phosphorylation of PDGFRA and c-KIT (Basciani et al. 2005).

One case of primary ovarian insufficiency during imatinib therapy was recently reported (Christopoulos et al. 2008); however, the report was later challenged as being overly speculative (Malozowski et al. 2008). In animal models, fertility in female rats has not been adversely affected by imatinib, and experience with the drug has shown pregnancies in women taking TKIs (Hensley \& Ford 2003, Robinson et al. 2007). Future long-term evaluation of the effects of TKIs on ovarian function and fertility are required.

\section{Pregnancy and TKIs}

As the use of TKIs becomes more widespread, the safety of these agents during pregnancy has been called into question in light of the potential risks to the fetus. Few data exist on the effect of TKIs on fetal growth and development, and current recommendations call for the use of effective contraception in young women undergoing treatment. However, in cases where alternative therapy or stopping therapy are not acceptable alternatives, these agents have been used during pregnancy, and some reports are available on outcomes of pregnancies in women taking TKIs. A review on the use of targeted treatment with TKIs during pregnancy was recently published (Robinson et al. 2007). Imatinib has been linked with low birth weight, and both erlotinib and lapatinib have been associated with oligohydramnios, necessitating the close ultrasound follow-up of growth and amniotic fluid index in these patients.

\section{Adrenal insufficiency}

Although overt adrenal insufficiency has not been reported in patients receiving TKIs, adrenal damage was observed in animal studies (Pfizer). Adrenal toxicity was reported in repeat dose studies performed in rats and monkeys at plasma exposures as low as 0.7 times the area under the curve observed in clinical studies. A number of histological changes of the adrenal gland were noted, including hemorrhage, necrosis, congestion, hypertrophy, and inflammation. In clinical studies, CT/magnetic resonance imaging obtained in 336 patients after exposure to one or more cycles of sunitinib failed to demonstrate evidence of adrenal hemorrhage or necrosis. ACTH stimulation testing was performed in $\sim 400$ patients across multiple clinical trials of sunitinib, with only one patient found to have consistently abnormal test results during treatment. Eleven additional patients with normal baseline testing had abnormalities in the final test performed, with peak cortisol levels of $12-16.4 \mu \mathrm{g} / \mathrm{dl}$ (normal $>18 \mu \mathrm{g} / \mathrm{dl}$ ) following stimulation. None of these patients were reported to have clinical evidence of adrenal insufficiency (Pfizer).

The hypothalamic-pituitary-adrenal (HPA) axis was evaluated in 25 patients with CML treated with imatinib using glucagon stimulation testing as well as low dose $(1 \mu \mathrm{g})$ ACTH testing. Twelve $(48 \%)$ of 
patients were defined as HPA deficient in this study (defined as a peak serum cortisol level $<18 \mu \mathrm{g} / \mathrm{dl}$ measured $30 \mathrm{~min}$ after i.v. delivery of $1 \mu \mathrm{g}$ of ACTH), indicating an increased prevalence of subclinical glucocorticoid deficiency in patients receiving imatinib (Bilgir et al. 2010). The Food and Drug Administration drug approval summary cautions that although no overt clinically important adrenal suppression has been observed in patients taking sunitinib, subclinical toxicity may be unmasked by physiologic stress; therefore, monitoring for adrenal insufficiency is recommended in patients undergoing stressors such as surgery, trauma, or severe infection (Rock et al. 2007).

\section{Glucose metabolism}

Increasing evidence suggests that TKIs influence glucose metabolism; both elevated and decreased blood glucose levels have been attributed to TKIs. The mechanism by which TKIs alter blood glucose levels is not known. Of the six FDA-approved TKIs, three of these agents, imatinib, sunitinib, and nilotinib have all been associated with apparently opposite effects on glucose metabolism.

Imatinib has been associated with the adverse reaction of hyperglycemia in $0.1-1 \%$ of patients as reported in the adjuvant GIST trial (Novartis). However, a number of reports in the literature have cited glucose-lowering effects thought to be associated with imatinib. A case of regression of long-standing type 2 diabetes during treatment of CML with imatinib was first reported in 2005 (Veneri et al. 2005). The authors postulated that inhibition of phosphorylation by imatinib may serve to improve insulin sensitivity. Another report revealed improvement of fasting blood glucose levels in six out of seven diabetic CML patients being treated with imatinib, allowing reduction in insulin dosage or oral antidiabetes therapy (Breccia et al. 2004). Two patients with GIST and hypoglycemia were reported, in whom imatinib is likely to have contributed to the severity of the hypoglycemia (Hamberg et al. 2006). In vitro studies have shown that imatinib enhances $\beta$-cell survival, potentially contributing to the glucose-lowering effects observed, thus far with the use of this TKI (Hagerkvist et al. 2007).

The prescribing information for sunitinib reports the incidence of hypoglycemia in 73 out of 375 patients (19\%) and hyperglycemia in 58 out of 375 patients (15\%; Pfizer). Proposed mechanisms include regression of pancreatic islets, modulation of insulinlike growth factor 1 signaling, or decreased glucose uptake. In metastatic renal carcinoma, hyperglycemia has been reported as a toxicity associated with the use of sunitinib in 15\% of cases (Guevremont et al. 2009). Blood glucose level variations associated with sunitinib therapy were retrospectively reviewed in 19 diabetic patients treated for RCC. All patients had a decrease in blood glucose level after 4 weeks of treatment (Billemont et al. 2008).

Updated data from the phase II trial of nilotinib for patients with CML listed hyperglycemia as a grade $3 / 4$ toxicity associated with $12 \%$ of patients taking this agent (Deremer et al. 2008). The prescribing information for nilotinib reports increased blood glucose as a common adverse reaction, occurring in $<5 \%$ of patients (Novartis). The increased reports of altered glucose levels in patients receiving TKIs are difficult to interpret, given that some agents are associated with both hyper and hypoglycemia. In diabetic patients, careful assessment of glycemic control while on TKIs is recommended. Monitoring $\mathrm{HbA} 1 \mathrm{c}$ and blood glucose levels periodically for nondiabetic patients while on treatment, as well as advising patients to report any excessive thirst or polyuria, are both reasonable recommendations.

\section{Conclusions}

Clinicians must be familiar with the recognition and management of endocrine-related side effects associated with TKIs. While an association between TKIs and TSH and parathyroid hormone (PTH) elevation has been established, the etiology behind these associations remains to be elucidated. Both the TSH and TRH receptors are members of the $G$ protein-coupled receptor (GPCR) superfamily, while the thyroid hormone receptor is a nuclear receptor; thus, none of the thyroid signaling pathway receptors belongs to the TK class. The same can be said for the PTH receptor 1, which is yet another GPCR regulating calcium ion homeostasis through the activation of adenylate cyclase and phospholipase C. In addition, the calcium-sensing receptor is another GPCR that acts by sensing extracellular levels of calcium and controls calcium homeostasis by regulating the release of PTH. Although these signaling cascades were once thought to be discrete, recent insights show integrated crosstalk between certain receptor tyrosine kinases (RTK) and GPCRs, whereby these signaling pathways merge to form complex signaling networks (Gavi et al. 2006). This 'cross talk' may have implications when considering drug side effects. A recent review highlighted the examples of TK activation modifying the function of GPCR (Gavi et al. 2006). One prominent example of this 'cross talk' is by both the insulin receptor and the b2 adrenergic receptor, whereby insulin receptor activation promotes the phosphorylation of the b2-AR both 
directly and indirectly; this well-studied example shows how insulin can counter regulate catecholamine action in the regulation of glucose metabolism. TKs modulate diverse GPCR, and thus impact physiological function. Both the TK and GPCR signaling pathways converge on the MAPK cascade. Crosstalk between these two types of receptors may occur both at the protein-protein interaction level and also downstream in the respective signaling cascades, potentially providing a mechanistic basis for these endocrinerelated side effects of TKIs. Further investigation is required to elucidate the exact molecular mechanisms underlying endocrine dysfunction in patients receiving TKIs.

\section{Declaration of interest}

The authors declare that there is no conflict of interest that could be perceived as prejudicing the impartiality of the review reported.

\section{Funding}

Supported by the Intramural Research Division of the Eunice Kennedy Shriver National Institute of Child Health and Human Development.

\section{Acknowledgements}

We would like to thank Nichole Jonas and Jeremy Swan for their assistance with graphic design.

\section{References}

Alvarez RH, Kantarjian HM \& Cortes JE 2006 Biology of platelet-derived growth factor and its involvement in disease. Mayo Clinic Proceedings 81 1241-1257. (doi:10.4065/81.9.1241)

Badros AZ, Siegel E, Bodenner D, Zangari M, Zeldis J, Barlogie B \& Tricot G 2002 Hypothyroidism in patients with multiple myeloma following treatment with thalidomide. American Journal of Medicine 112 412-413. (doi:10.1016/S0002-9343(01)01137-8)

Ballardini P, Margutti G, Aliberti C \& Manfredini R 2009 Onset of male gynaecomastia in a patient treated with sunitinib for metastatic renal cell carcinoma. Clinical Drug Investigation 29 487-490. (doi:10.2165/00044011200929070-00007)

Basciani S, Mariani S, Arizzi M, Ulisse S, Rucci N, Jannini EA, Della Rocca C, Manicone A, Carani C, Spera G et al. 2002 Expression of platelet-derived growth factor-A (PDGF-A), PDGF-B, and PDGF receptor-alpha and -beta during human testicular development and disease. Journal of Clinical Endocrinology and Metabolism 87 2310-2319. (doi:10.1210/jc.87.5.2310)
Basciani S, Brama M, Mariani S, De Luca G, Arizzi M, Vesci L, Pisano C, Dolci S, Spera G \& Gnessi L 2005 Imatinib mesylate inhibits Leydig cell tumor growth: evidence for in vitro and in vivo activity. Cancer Research 65 1897-1903. (doi:10.1158/0008-5472.CAN-04-2181)

Berman E, Nicolaides M, Maki RG, Fleisher M, Chanel S, Scheu K, Wilson BA, Heller G \& Sauter NP 2006 Altered bone and mineral metabolism in patients receiving imatinib mesylate. New England Journal of Medicine 354 2006-2013. (doi:10.1056/NEJMoa051140)

Bilgir O, Kebapcilar L, Bilgir F, Sari I, Oner P, Karaca B \& Alacacioglu I 2010 Is there any relationship between imatinib mesylate medication and hypothalamic-pituitary-adrenal axis dysfunction? International Journal of Clinical Practice 64 45-50. (doi:10.1111/j.1742-1241. 2008.01856.x)

Billemont B, Medioni J, Taillade L, Helley D, Meric JB, Rixe O \& Oudard S 2008 Blood glucose levels in patients with metastatic renal cell carcinoma treated with sunitinib. British Journal of Cancer 99 1380-1382. (doi:10.1038/sj.bjc.6604709)

Breccia M, Muscaritoli M, Aversa Z, Mandelli F \& Alimena G 2004 Imatinib mesylate may improve fasting blood glucose in diabetic $\mathrm{Ph}+$ chronic myelogenous leukemia patients responsive to treatment. Journal of Clinical Oncology 22 4653-4655. (doi:10.1200/JCO. 2004.04.217)

Caocci G, Atzeni S, Orru N, Azzena L, Martorana L, Littera R, Ledda A \& La Nasa G 2008 Gynecomastia in a male after dasatinib treatment for chronic myeloid leukemia. Leukemia 22 2127-2128. (doi:10.1038/leu. 2008.106)

Christopoulos C, Dimakopoulou V \& Rotas E 2008 Primary ovarian insufficiency associated with imatinib therapy. New England Journal of Medicine 358 1079-1080. (doi:10.1056/NEJMc0707841)

Chu TF, Rupnick MA, Kerkela R, Dallabrida SM, Zurakowski D, Nguyen L, Woulfe K, Pravda E, Cassiola F, Desai J et al. 2007 Cardiotoxicity associated with tyrosine kinase inhibitor sunitinib. Lancet $\mathbf{3 7 0}$ 2011-2019. (doi:10.1016/S0140-6736(07)61865-0)

Ciampi R \& Nikiforov YE 2007 RET/PTC mutations in thyroid tumorigenesis. Endocrinology 148 936-941. (doi:10.1210/en.2006-0921)

Darzy KH \& Shalet SM 2009 Hypopituitarism following radiotherapy. Pituitary 12 40-50. (doi:10.1007/s11102008-0088-4)

Daub H 2010 Kinase inhibitors: narrowing down the real targets. Nature Chemical Biology 6 249-250. (doi:10. 1038/nchembio.336)

Deremer DL, Ustun C \& Natarajan K 2008 Nilotinib: a second-generation tyrosine kinase inhibitor for the treatment of chronic myelogenous leukemia. Clinical Therapeutics 30 1956-1975. (doi:10.1016/j.clinthera. 2008.11.014)

Desai J, Yassa L, Marqusee E, George S, Frates MC, Chen MH, Morgan JA, Dychter SS, Larsen PR, Demetri GD 
et al. 2006 Hypothyroidism after sunitinib treatment for patients with gastrointestinal stromal tumors. Annals of Internal Medicine 145 660-664.

Dora JM, Leie MA, Netto B, Fogliatto LM, Silla L, Torres F \& Maia AL 2008 Lack of imatinib-induced thyroid dysfunction in a cohort of non-thyroidectomized patients. European Journal of Endocrinology 158 771-772. (doi:10.1530/EJE-08-0006)

Fabian MA, Biggs WH III, Treiber DK, Atteridge CE, Azimioara MD, Benedetti MG, Carter TA, Ciceri P, Edeen PT, Floyd M et al. 2005 A small molecule-kinase interaction map for clinical kinase inhibitors. Nature Biotechnology 23 329-336. (doi:10.1038/nbt1068)

Faris JE, Moore AF \& Daniels GH 2007 Sunitinib (sutent)induced thyrotoxicosis due to destructive thyroiditis: a case report. Thyroid 17 1147-1149. (doi:10.1089/thy. 2007.0104)

Fitter S, Dewar AL, Kostakis P, To LB, Hughes TP, Roberts MM, Lynch K, Vernon-Roberts B \& Zannettino AC 2008 Long-term imatinib therapy promotes bone formation in CML patients. Blood 111 2538-2547. (doi:10.1182/ blood-2007-07-104281)

Fox E, Widemann B, Whitcomb PO, Aikin A, Dombi E, Lodish M, Stratakis CA, Steinberg S, Wells SA Jr \& Balis FM 2009 Phase I/II trial of vandetanib in children and adolescents with hereditary medullary thyroid carcinoma. Journal of Clinical Oncology 27 (Supplement 15S) abstract 10014.

Gambacorti-Passerini C, Tornaghi L, Cavagnini F, Rossi P, Pecori-Giraldi F, Mariani L, Cambiaghi N, Pogliani E, Corneo G \& Gnessi L 2003 Gynaecomastia in men with chronic myeloid leukaemia after imatinib. Lancet 361 1954-1956. (doi:10.1016/S0140-6736(03)13554-4)

Garcia-Serra A, Amdur RJ, Morris CG, Mazzaferri E \& Mendenhall WM 2005 Thyroid function should be monitored following radiotherapy to the low neck. American Journal of Clinical Oncology 28 255-258. (doi:10.1097/01.coc.0000145985.64640.ac)

Gavi S, Shumay E, Wang HY \& Malbon CC 2006 G-proteincoupled receptors and tyrosine kinases: crossroads in cell signaling and regulation. Trends in Endocrinology and Metabolism 17 48-54. (doi:10.1016/j.tem.2006.01.006)

Gerber HP, Vu TH, Ryan AM, Kowalski J, Werb Z \& Ferrara N 1999 VEGF couples hypertrophic cartilage remodeling, ossification and angiogenesis during endochondral bone formation. Nature Medicine 5 623-628. (doi:10.1038/ 9467)

Grey A, O’Sullivan S, Reid IR \& Browett P 2006 Imatinib mesylate, increased bone formation, and secondary hyperparathyroidism. New England Journal of Medicine 355 2494-2495. (doi:10.1056/NEJMc062388)

de Groot JW, Zonnenberg BA, Plukker JT, van Der Graaf WT \& Links TP 2005 Imatinib induces hypothyroidism in patients receiving levothyroxine. Clinical Pharmacology and Therapeutics 78 433-438. (doi:10.1016/j.clpt.2005. 06.010) de Groot JW, Zonnenberg BA, van Ufford-Mannesse PQ, de Vries MM, Links TP, Lips CJ \& Voest EE 2007 A phase II trial of imatinib therapy for metastatic medullary thyroid carcinoma. Journal of Clinical Endocrinology and Metabolism 92 3466-3469. (doi:10.1210/jc.2007-0649)

Grossmann M, Premaratne E, Desai J \& Davis ID 2008 Thyrotoxicosis during sunitinib treatment for renal cell carcinoma. Clinical Endocrinology 69 669-672. (doi:10. 1111/j.1365-2265.2008.03253.x)

Guevremont C, Alasker A \& Karakiewicz PI 2009 Management of sorafenib, sunitinib, and temsirolimus toxicity in metastatic renal cell carcinoma. Current Opinion in Supportive and Palliative Care 3 170-179. (doi:10.1097/ SPC.0b013e32832e4681)

Gupta-Abramson V, Troxel AB, Nellore A, Puttaswamy K, Redlinger M, Ransone K, Mandel SJ, Flaherty KT, Loevner LA, O'Dwyer PJ et al. 2008 Phase II trial of sorafenib in advanced thyroid cancer. Journal of Clinical Oncology 26 4714-4719. (doi:10.1200/JCO.2008.16. 3279)

Hagerkvist R, Sandler S, Mokhtari D \& Welsh N 2007 Amelioration of diabetes by imatinib mesylate (Gleevec): role of $\beta$-cell NF- $\kappa \mathrm{B}$ activation and anti-apoptotic preconditioning. FASEB Journal 21 618-628. (doi:10. 1096/fj.06-6910com)

Hamberg P, de Jong FA, Boonstra JG, van Doorn J, Verweij J \& Sleijfer S 2006 Non-islet-cell tumor induced hypoglycemia in patients with advanced gastrointestinal stromal tumor possibly worsened by imatinib. Journal of Clinical Oncology 24 e30-e31. (doi:10.1200/JCO.2006.06.5318)

Hensley ML \& Ford JM 2003 Imatinib treatment: specific issues related to safety, fertility, and pregnancy. Seminars in Hematology 40 21-25.

Jabbour E, Cortes JE, Giles FJ, O’Brien S \& Kantarjian HM 2007 Current and emerging treatment options in chronic myeloid leukemia. Cancer 109 2171-2181. (doi:10.1002/ cncr.22661)

Jonsson S, Olsson B, Ohlsson C, Lorentzon M, Mellstrom D \& Wadenvik H 2008 Increased cortical bone mineralization in imatinib treated patients with chronic myelogenous leukemia. Haematologia 93 1101-1103. (doi:10.3324/haematol.12373)

Karaman MW, Herrgard S, Treiber DK, Gallant P, Atteridge CE, Campbell BT, Chan KW, Ciceri P, Davis MI, Edeen PT et al. 2008 A quantitative analysis of kinase inhibitor selectivity. Nature Biotechnology 26 127-132. (doi:10. 1038/nbt1358)

Kim H, Chang HM, Ryu MH, Kim TW, Sohn HJ, Kim SE, Kang HJ, Park S, Lee JS \& Kang YK 2005 Concurrent male gynecomastia and testicular hydrocele after imatinib mesylate treatment of a gastrointestinal stromal tumor. Journal of Korean Medical Science 20 512-515. (doi:10. 3346/jkms.2005.20.3.512)

Kimoto T, Inoue M \& Kawa K 2009 Growth deceleration in a girl treated with imatinib. International Journal of Hematology 89 251-252. (doi:10.1007/s12185-0080251-8) 
Kloos RT, Ringel MD, Knopp MV, Hall NC, King M, Stevens R, Liang J, Wakely PE Jr, Vasko VV, Saji M et al. 2009 Phase II trial of sorafenib in metastatic thyroid cancer. Journal of Clinical Oncology 27 1675-1684. (doi:10.1200/JCO.2008.18.2717)

Krause DS \& Van Etten RA 2005 Tyrosine kinases as targets for cancer therapy. New England Journal of Medicine 353 172-187. (doi:10.1056/NEJMra044389)

Kulke MH, Lenz HJ, Meropol NJ, Posey J, Ryan DP, Picus J, Bergsland E, Stuart K, Tye L, Huang X et al. 2008 Activity of sunitinib in patients with advanced neuroendocrine tumors. Journal of Clinical Oncology 26 3403-3410. (doi:10.1200/JCO.2007.15.9020)

Lodish MB \& Stratakis CA 2008 RET oncogene in MEN2, MEN2B, MTC and other forms of thyroid cancer. Expert Review of Anticancer Therapy 8 625-632. (doi:10.1586/ 14737140.8.4.625)

Makita N, Miyakawa M, Fujita T \& Iiri T 2010 Sunitinib induces hypothyroidism with a markedly reduced vascularity. Thyroid 20 323-326. (doi:10.1089/thy.2009.0414)

Malozowski S, Nelson L \& Calis KA 2008 More on ovarian insufficiency with imatinib. New England Journal of Medicine 3582648 (author reply 2648-2649). (doi:10. 1056/NEJMc080707)

Mannavola D, Coco P, Vannucchi G, Bertuelli R, Carletto M, Casali PG, Beck-Peccoz P \& Fugazzola L 2007 A novel tyrosine-kinase selective inhibitor, sunitinib, induces transient hypothyroidism by blocking iodine uptake. Journal of Clinical Endocrinology and Metabolism 92 3531-3534. (doi:10.1210/jc.2007-0586)

Mariani S, Giona F, Basciani S, Brama M \& Gnessi L 2008 Low bone density and decreased inhibin-B/FSH ratio in a boy treated with imatinib during puberty. Lancet 372 111-112. (doi:10.1016/S0140-6736(08)61023-5)

Martorella AJ, Omry G, Hann LE, Motzer RJ, Robbins RJ 2006 Receptor kinase (RTK) inhibitor SU11248 may cause hypothyroidism in a select group of patients with metastatic renal cell carcinoma (RCC). In Proceedings of 88th Annual Meeting of the Endocrine Society, abstract 593. Endocrine Society, Boston, MA, USA.

Meric-Bernstam F \& Gonzalez-Angulo AM 2009 Targeting the mTOR signaling network for cancer therapy. Journal of Clinical Oncology 27 2278-2287. (doi:10. 1200/JCO.2008.20.0766)

Osorio S, Noblejas AG, Duran A \& Steegmann JL 2007 Imatinib mesylate induces hypophosphatemia in patients with chronic myeloid leukemia in late chronic phase, and this effect is associated with response. American Journal of Hematology 82 394-395. (doi:10.1002/ajh.20778)

O'Sullivan S, Naot D, Callon K, Porteous F, Horne A, Wattie D, Watson M, Cornish J, Browett P \& Grey A 2007 Imatinib promotes osteoblast differentiation by inhibiting PDGFR signaling and inhibits osteoclastogenesis by both direct and stromal cell-dependent mechanisms. Journal of Bone and Mineral Research 22 1679-1689. (doi:10.1359/ jbmr.070719)
O'Sullivan S, Horne A, Wattie D, Porteous F, Callon K, Gamble G, Ebeling P, Browett P \& Grey A 2009 Decreased bone turnover despite persistent secondary hyperparathyroidism during prolonged treatment with imatinib. Journal of Clinical Endocrinology and Metabolism 94 1131-1136. (doi:10.1210/jc.2008-2324)

Pacini F, Sherman S, Schlumberger M, Elisei R, Wirth L, Bastholt L, Droz JP, Martins R, Hofmann M, Locati L et al. 2007 Exacerbation of postsurgical hypothyroidism during treatment of advanced differentiated (DTC) or medullary (MTC) thyroid carcinoma with AMG 706. Hormone Research 6829.

Raymond E 2010 Updated results of the phase III trial of sunitinib (SU) versus placebo (PBO) for treatment of advanced pancreatic neuroendocrine tumors (NET). In Proceedings of the 2010 Annual Meeting of the American Society of Clinical Oncology, abstract 127. ASCO, Chicago, IL, USA.

Ren R 2005 Mechanisms of BCR-ABL in the pathogenesis of chronic myelogenous leukaemia. Nature Reviews. Cancer 5 172-183. (doi:10.1038/nrc1567)

Rini BI, Tamaskar I, Shaheen P, Salas R, Garcia J, Wood L, Reddy S, Dreicer R \& Bukowski RM 2007 Hypothyroidism in patients with metastatic renal cell carcinoma treated with sunitinib. Journal of the National Cancer Institute 99 81-83. (doi:10.1093/jnci/djk008)

Robinson AA, Watson WJ \& Leslie KK 2007 Targeted treatment using monoclonal antibodies and tyrosinekinase inhibitors in pregnancy. Lancet Oncology 8 738-743. (doi:10.1016/S1470-2045(07)70242-5)

Rock EP, Goodman V, Jiang JX, Mahjoob K, Verbois SL, Morse D, Dagher R, Justice R \& Pazdur R 2007 Food and drug administration drug approval summary: sunitinib malate for the treatment of gastrointestinal stromal tumor and advanced renal cell carcinoma. Oncologist 12 107-113. (doi:10.1634/theoncologist.12-1-107)

Rogiers A, Wolter P, Op de Beeck K, Thijs M, Decallonne B \& Schoffski P 2010 Shrinkage of thyroid volume in sunitinib-treated patients with renal-cell carcinoma: a potential marker of irreversible thyroid dysfunction? Thyroid 20 317-322. (doi:10.1089/thy.2009.0125)

Rubin BP, Heinrich MC \& Corless CL 2007 Gastrointestinal stromal tumour. Lancet 369 1731-1741. (doi:10.1016/ S0140-6736(07)60780-6)

Sabatier R, Gravis G, Deville J, Salem N, Brunelle S, Walz J, Marcy M, Narbonne H, Viens P, Bladou F; Institut Paoli Calmettes, Marseille, France; CHU Marseille, Hopital La Timone, Marseille, France; CHU Marseille, Hopital Sainte Marguerite, Marseille, France 2009 Hypothyroidism and survival during sunitinib therapy in metastatic renal cell cancer: a prospective observational analysis. In Proceedings of the 2009 Genitourinary Cancers Symposium, ASCO, abstract 317. ASCO, Orlando, FL, USA.

Salem AK, Fenton MS, Marion KM \& Hershman JM 2008 Effect of sunitinib on growth and function of FRTL-5 thyroid cells. Thyroid 18 631-635. (doi:10.1089/thy. 2007.0336) 
Schlessinger J 2000 Cell signaling by receptor tyrosine kinases. Cell 103 211-225. (doi:10.1016/S00928674(00)00114-8)

Schlumberger MJ, Elisei R, Bastholt L, Wirth LJ, Martins RG, Locati LD, Jarzab B, Pacini F, Daumerie C, Droz JP et al. 2009 Phase II study of safety and efficacy of motesanib in patients with progressive or symptomatic, advanced or metastatic medullary thyroid cancer. Journal of Clinical Oncology 27 3794-3801. (doi:10. 1200/JCO.2008.18.7815)

Schmid H, Jaeger BA, Lohse J \& Suttorp M 2009 Longitudinal growth retardation in a prepuberal girl with chronic myeloid leukemia on long-term treatment with imatinib. Haematologia 94 1177-1179. (doi:10.3324/ haematol.2009.008359)

Schoeffski P, Wolter P, Himpe U, Dychter SS, Baum C, Prenen H, Wildiers H, Bex M \& Dumez H 2006 Sunitinibrelated thyroid dysfunction: a single-center retrospective and prospective evaluation. Journal of Clinical Oncology. ASCO Meeting Abstracts 243092.

Sebolt-Leopold JS 2008 Advances in the development of cancer therapeutics directed against the RAS-mitogen-activated protein kinase pathway. Clinical Cancer Research 14 3651-3656. (doi:10.1158/1078-0432.CCR-08-0333)

Shaheen PE, Tamaskar IR, Salas RN, Rini BI, Garcia J, Wood L, Dreicer R, Bukowski RM 2006 Thyroid function tests (TFTs) abnormalities in patients (pts) with metastatic renal cell carcinoma (mRCC) treated with sunitinib. Journal of Clinical Oncology 24 (Supplement 18S) abstract 4605.

Sherman SI 2009a Advances in chemotherapy of differentiated epithelial and medullary thyroid cancers. Journal of Clinical Endocrinology and Metabolism 94 1493-1499. (doi:10.1210/jc.2008-0923)

Sherman SI $2009 b$ Tyrosine kinase inhibitors and the thyroid. Best Practice and Research. Clinical Endocrinology and Metabolism 23 713-722. (doi:10.1016/j.beem.2009.08. 001)

Sherman SI, Gopal J, Haugen BR, Chiu AC, Whaley K, Nowlakha P \& Duvic M 1999 Central hypothyroidism associated with retinoid $\mathrm{X}$ receptor-selective ligands. New England Journal of Medicine 340 1075-1079. (doi:10.1056/NEJM199904083401404)

Sherman SI, Wirth LJ, Droz JP, Hofmann M, Bastholt L, Martins RG, Licitra L, Eschenberg MJ, Sun YN, Juan T et al. 2008 Motesanib diphosphate in progressive differentiated thyroid cancer. New England Journal of Medicine 359 31-42. (doi:10.1056/NEJMoa075853)

Suttorp M, Boehme J, Vaitl J, Mosch B, Pursche S, Jung R, Bergmann R, Fischer R, Pietzsch J, Bornhaeuser M et al. 2008 Side effects on the heart and skeleton of growing mice attributed to chronic imatinib exposure. Blood 112402.

Tamaskar I, Bukowski R, Elson P, Ioachimescu AG, Wood L, Dreicer R, Mekhail T, Garcia J \& Rini BI 2008 Thyroid function test abnormalities in patients with metastatic renal cell carcinoma treated with sorafenib. Annals of Oncology 19 265-268. (doi:10.1093/annonc/mdm483)
Torino F, Corsello SM, Longo R, Barnabei A \& Gasparini G 2009 Hypothyroidism related to tyrosine kinase inhibitors: an emerging toxic effect of targeted therapy. Nature Reviews. Clinical Oncology 6 219-228. (doi:10. 1038/nrclinonc.2009.4)

Tortora G, Ciardiello F \& Gasparini G 2008 Combined targeting of EGFR-dependent and VEGF-dependent pathways: rationale, preclinical studies and clinical applications. Nature Clinical Practice \& Oncology 5 521-530. (doi:10.1038/ncponc1161)

Vandyke K, Dewar AL, Fitter S, Menicanin D, To LB, Hughes TP \& Zannettino AC 2009 Imatinib mesylate causes growth plate closure in vivo. Leukemia $\mathbf{2 3}$ 2155-2159. (doi:10.1038/leu.2009.150)

Vandyke K, Dewar AL, Diamond P, Fitter S, Schultz CG, Sims NA \& Zannettino AC 2010 The tyrosine kinase inhibitor dasatinib dysregulates bone remodelling through inhibition of osteoclasts in vivo. Journal of Bone and Mineral Research [in press]. (doi:10.1002/jbmr.85)

Veneri D, Franchini M \& Bonora E 2005 Imatinib and regression of type 2 diabetes. New England Journal of Medicine 352 1049-1050. (doi:10.1056/NEJM2005 03103521023)

Weijl NI, Van der Harst D, Brand A, Kooy Y, Van Luxemburg S, Schroder J, Lentjes E, Van Rood JJ, Cleton FJ \& Osanto S 1993 Hypothyroidism during immunotherapy with interleukin-2 is associated with antithyroid antibodies and response to treatment. Journal of Clinical Oncology 11 1376-1383.

Wells SA Jr \& Santoro M 2009 Targeting the RET pathway in thyroid cancer. Clinical Cancer Research 15 7119-7123. (doi:10.1158/1078-0432.CCR-08-2742)

Wells SA Jr, Gosnell JE, Gagel RF, Moley J, Pfister D, Sosa JA, Skinner M, Krebs A, Vasselli J \& Schlumberger M 2010 Vandetanib for the treatment of patients with locally advanced or metastatic hereditary medullary thyroid cancer. Journal of Clinical Oncology 28 767-772. (doi:10.1200/JCO.2009.23.6604)

Widakowich C, de Castro G Jr, de Azambuja E, Dinh P \& Awada A 2007 Review: side effects of approved molecular targeted therapies in solid cancers. Oncologist 12 1443-1455. (doi:10.1634/theoncologist.12-12-1443)

Wolter P, Stefan C, Decallonne B, Dumez H, Bex M, Carmeliet P \& Schoffski P 2008 The clinical implications of sunitinib-induced hypothyroidism: a prospective evaluation. British Journal of Cancer 99 448-454. (doi:10.1038/sj.bjc.6604497)

Wong E, Rosen LS, Mulay M, Vanvugt A, Dinolfo M, Tomoda C, Sugawara M \& Hershman JM 2007 Sunitinib induces hypothyroidism in advanced cancer patients and may inhibit thyroid peroxidase activity. Thyroid $\mathbf{1 7}$ 351-355. (doi:10.1089/thy.2006.0308)

Xing M 2005 BRAF mutation in thyroid cancer. EndocrineRelated Cancer 12 245-262. (doi:10.1677/erc.1.0978)

Zhang J, Yang PL \& Gray NS 2009 Targeting cancer with small molecule kinase inhibitors. Nature Reviews. Cancer 9 28-39. (doi:10.1038/nrc2559) 